\title{
Production of Tetraploid and Triploid Hemp
}

\author{
Lauren E. Kurtz, Mark H. Brand, and Jessica D. Lubell-Brand \\ Department of Plant Science and Landscape Architecture, University of \\ Connecticut, 1376 Storrs Road, Unit 4067, Storrs, CT 06269-4067
}

Additional index words. Cannabis sativa, colchicine, embryo rescue, flow cytometry, pregerminated seed

\begin{abstract}
To maximize yield, cannabidiol (CBD) hemp producers prefer female plants, and this is accomplished by using expensive feminized seed, vegetatively propagated female clones, or by removing male plants from dioecious seed lots. Hemp pollen drifts long distances on wind, and pollination of females reduces CBD content. Induction of triploidy is a common strategy used by plant breeders to produce sterile cultivars of agricultural crops. Triploid ( $3 n$ ) hemp, with three sets of chromosomes, was developed by crossing naturally diploid (2n) hemp with tetraploid (4n) hemp. Tetraploid plants used to create triploids were produced using pregerminated seeds and the mitotic spindle inhibitor colchicine. Seedlings from seeds of 'Abacas' $\times\left[\left({ }^{\prime} \mathrm{Otto2}\right.\right.$ ' $\times$ ' $\mathrm{BaOx}$ ' $) \times\left({ }^{\circ} \mathrm{BaOx}\right.$ ' $\times$ 'Colorado Cherry')] treated with $0.05 \%$ colchicine or $0.02 \%$ colchicine for 12 hours and longer were significantly shorter than controls and $\leq 1 \mathrm{~cm}$ tall at 10 days after sowing. Surviving seedlings exhibited thickened cotyledons and hypocotyls, which indicated a potential change in ploidy. Tetraploid induction ranged from $26 \%$ to $64 \%$ for pregerminated seeds of five different hemp cultivars (Abacus $\times$ Wife, Cherry Wine, Mountain Mango, Wife, and Youngsim10) treated with $0.05 \%$ colchicine for 12 hours. Tetraploids had nearly twice the DNA content as diploids according to flow cytometric analysis. Tetraploid 'Wife' had larger stomates and reduced stomatal density compared with diploid 'Wife'. Four triploid 'Wife' genotypes produced from crossing tetraploid 'Wife' with diploid 'Wife' were acclimated to greenhouse conditions after embryo rescue. DNA content and stomate size of triploid 'Wife' was intermediate between the parents. This is the first report of triploid plants of hemp. Future research will evaluate the sterility of triploid hemp.
\end{abstract}

Cannabis sativa (hemp, marijuana) is a dioecious species with homogametic (XX) pistillate female plants and heterogametic (XY) staminate male plants (Moliterni et al., 2004). The species is cultivated for cannabinoids, most notably CBD and tetrahydrocannabinol (THC), fiber, and grain, from which a wide range of consumer products are derived (Small, 2015). Cannabinoids have reported medicinal value and are produced in the glandular trichomes of the plant, which are found in the greatest density on the inflorescences of female plants (Small and Cronquist, 1976). Hemp is distinguished from marijuana by the content of THC produced by the plant, which is less than $0.3 \%$ dry weight THC for hemp (Agriculture Marketing Service, 2019). Hemp fiber is produced from the stalks and the seed is harvested for grain and hempseed oil (Small, 2015). Monecious cultivars have been developed for dualpurpose fiber and grain production.

Hemp seed from open-pollinated dioecious plants can be expected to produce a

Received for publication 13 July 2020. Accepted for publication 14 Aug. 2020.

Published online 18 September 2020

J.D.L.-B. is the corresponding author. E-mail: Jessica.lubell@uconn.edu.

This is an open access article distributed under the CC BY-NC-ND license (https://creativecommons. org/licenses/by-nc-nd/4.0/).
50:50 ratio of male-to-female plants (Small, 2015). During CBD hemp production, it is important for growers to remove male plants before anthesis, because pollination of female plants reduces cannabinoid yield (Meier and Mediavilla, 1998). Hemp growers prefer to use feminized seed or vegetatively propagated female clones for CBD production to eliminate the labor of removing male plants and the lost acreage from removed male plants. Hemp is wind-pollinated, and pollen can drift long distances (Small, 2015). It has been reported that hemp pollen can drift more than $300 \mathrm{~km}$ (Clarke, 1977). Therefore, even when hemp farmers take strict measures to grow only female plants, they can experience seed production as a result of drifting pollen from neighboring fiber and grain farms or from $\mathrm{CBD}$ farms that did not remove males. A distance of at least $5 \mathrm{~km}$ is recommended to prevent pollen drift from neighboring hemp fields (Neiden, 2020; Small, 2015). Disputes between farmers over unintended seed production from drifting pollen has led to several lawsuits (Perkowski, 2019). Pollen can also drift from wild or escaped hemp, known as ditch weed (Neiden, 2020).

Induction of polyploidy has been used by plant breeders to develop improved horticultural crops with enhanced traits such as size, vigor, and metabolite content (Alexander, 2017; Lehrer et al., 2008; Sattler et al., 2016; Wang et al., 2016; Xu et al., 2014).
Tetraploids are polyploids that contain four sets of chromosomes. Compared with diploids, tetraploid purple cone flower produces more secondary metabolites and biomass $(\mathrm{Xu}$ et al., 2014), and tetraploid ryegrass is more drought tolerant and disease resistant (Sattler et al., 2016). Tetraploidy can be induced artificially using mitotic spindle inhibitors such as colchicine or oryzalin (Sattler et al., 2016; Wang et al., 2016). C. sativa is almost exclusively diploid $(2 \mathrm{n}=20)$ in the wild (Small and Cronquist, 1976). There is only one report of a natural tetraploid of $C$. sativa, from India (Sharma et al., 2015). Tetraploid C. sativa has been produced using colchicine on seedling shoot tips (Bagheri and Mansouri, 2015; Mansouri and Bagheri, 2017), and by using oryzalin on in vitro nodal explants (Parsons et al., 2019). Tetraploid plants produced in these studies exhibited traits such as larger leaves and greater shoot fresh weight and flavonoid content.

Tetraploid plants crossed with diploid plants can generate triploid plants, which have three sets of chromosomes (Wang et al., 2016). Triploid plants are frequently seedless, because unequal segregation of chromosome pairs during meiosis results in inviable gametes (Wang et al., 2016). Seedless triploid cultivars have been bred for hops, watermelon, banana, and citrus (Trojak-Goluch and Skomra, 2018; Wang et al., 2016). Warmke and Davidson (1944) reported crossing tetraploid and diploid marijuana and producing triploid plants; however, no cytogenetic evidence of triploidy was provided. The objective of this work was to investigate a more efficient and easy method for inducing tetraploidy in hemp, and to cross tetraploid plants with diploid plants to produce triploid hemp. Triploid hemp that does not produce seed when exposed to pollen could be a solution for the problem of pollen drift.

\section{Materials and Methods}

Tetraploid development. Two experiments were conducted to produce tetraploid hemp plants by treating pregerminated seeds with colchicine. In Expt. 1, pregerminated seeds of 'Abacas' $\times$ [('Otto2' $\times$ 'BaOx') $\times$ ('BaOx' $\times$ 'Colorado Cherry')] were exposed to two colchicine concentrations $(0.02 \%$ or $0.05 \%)$ for three durations $(6,12$, or $24 \mathrm{~h})$ to determine a suitable exposure rate for tetraploid induction. Control pregerminated seeds were treated with water for $24 \mathrm{~h}$. In Expt. 2, pregerminated seeds of five different hemp cultivars (Abacus $\times$ Wife, Cherry Wine, Mountain Mango, Wife, and Youngsim10) were treated with $0.05 \%$ colchicine for $12 \mathrm{~h}$ to generate additional tetraploid genotypes. Seeds were pregerminated by soaking them in water for $24 \mathrm{~h}$ and then transferring them to $100-\times 15-\mathrm{mm}$ petri dishes lined with moistened filter paper (Whatman no. 4; Whatman, Maidstone, UK) for another $24 \mathrm{~h}$. After this treatment, seeds were considered pregerminated because radicals had emerged from 1 to $5 \mathrm{~mm}$ (Fig. 1A). For the colchicine treatment, 
pregerminated seeds were placed in $50-\mathrm{mL}$ conical tubes that were agitated gently at a slow speed on a platform shaker for the duration of treatment.

For Expt. 1, there were 25 pregerminated seeds per treatment, for a total of 175 seeds. For Expt. 2, the number of pregerminated seeds treated per cultivar varied because of limited seed availability. After colchicine treatment, seeds were rinsed with deionized water and sown to a depth of 6 to $8 \mathrm{~mm}$ in 50cell plug trays using a peatmoss-based seed starting mix (Fafard 3B Mix; Sungro Horticulture, Agawam, MA). For Expt. 1, seedlings were grown in a randomized complete block design, with five seedlings per experimental unit and five blocks $(n=5)$. Plants from both experiments were grown in a greenhouse with set points of $21{ }^{\circ} \mathrm{C} / 17{ }^{\circ} \mathrm{C}$ day/night under long-day conditions $(18 \mathrm{~h}$ light). Plants were fertigated as needed with a soluble fertilizer (Peters 20N-8.7P-16.6K; Scotts, Marysville, $\mathrm{OH}$ ), providing $100 \mathrm{ppm}$ nitrogen $(\mathrm{N})$. On day 10 after sowing, percent emergence and seedling height were recor- ded. Pregerminated seeds were considered emerged if cotyledons were visible above the soil surface. Percent emergence was calculated by dividing the number of seedlings emerged by the total number of seeds sown. For Expt. 1, percent emergence was calculated per experimental unit. Tetraploid induction rate was calculated by dividing the number of tetraploids produced by the total number of seeds treated, and then multiplying by $100 \%$. Data were subjected to analysis of variance (ANOVA) (Proc GLM) using SAS (version 9.4; SAS Institute, Cary, NC). Mean separation using Tukey's honestly significant difference test $(P \leq 0.05)$ was performed for percent emergence and seedling height.

Triploid development. On 5 Dec. 2019, three clonal plants each of two tetraploid, female 'Wife' genotypes (W1 and W2), established in 2-gallon containers filled with a peatmoss-based potting mix (Promix BK25; Premier Tech Horticulture, Quakertown, PA), were provided short days ( $12 \mathrm{~h}$ ) to induce flowering in a greenhouse with set
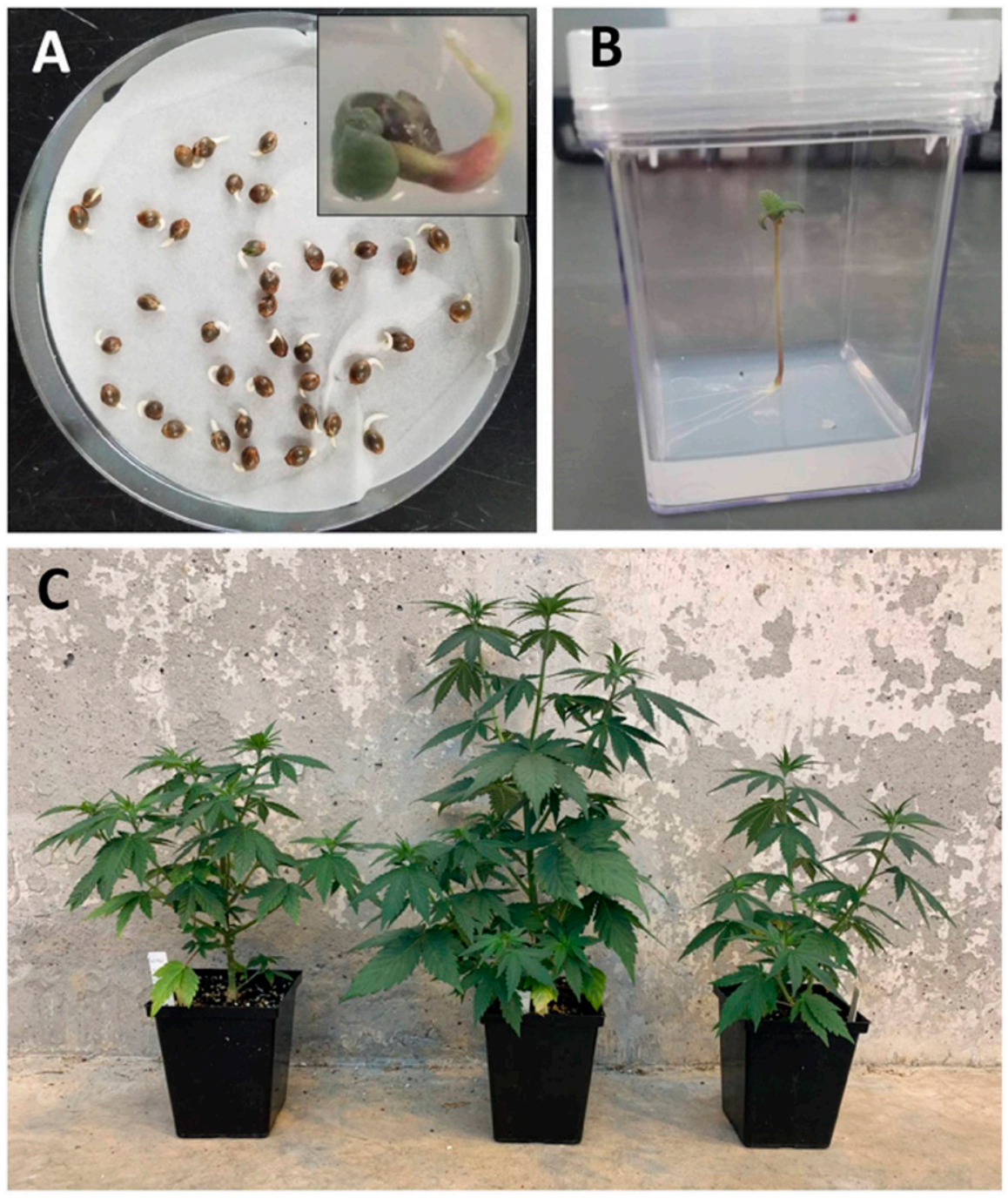

Fig. 1. Photographs of (A) pregerminated seeds with insert showing thickened hypocotyl of colchicinetreated seedling $(\mathbf{B})$ germinated, and rescued triploid embryo $(\mathbf{C})$ three triploid genotypes of parentage $\mathrm{W} 1 \times$ 'Wife' established in 1-L containers. points of $21{ }^{\circ} \mathrm{C} / 17^{\circ} \mathrm{C}$ day/night. In addition, four diploid, female, clonal 'Wife' plants established in 1-gallon containers using the same potting mix were also provided short days in the same greenhouse. Plants were top-dressed with controlled-release fertilizer (Osmocote Plus 15N-3.9P-10K 5- to 6-month formulation; Everris NA, Dublin, $\mathrm{OH})$ at $10 \mathrm{~g}$ per 1 -gallon container and $30 \mathrm{~g}$ per 2-gallon container. Plants received a soluble fertilizer (Peters $15 \mathrm{~N}-12.9 \mathrm{P}-$ $12.5 \mathrm{~K}$, Scotts) providing $100 \mathrm{ppm} \mathrm{N}$ at every irrigation $(1 \mathrm{~L} / \mathrm{d}$ and $2 \mathrm{~L} / \mathrm{d}$ for 1 gallon and 2-gallon container plants, respectively). On the first day of short days, diploid plants were sprayed with silver thiosulfate solution at a concentration of $3 \mathrm{~mm}$ prepared according to Lubell and Brand (2018) to induce male flower development. These plants were sprayed to runoff $(\approx 200 \mathrm{~mL} /$ plant $)$ on three occasions, $7 \mathrm{~d}$ apart, on 5 Dec., 12 Dec., and 19 Dec. 2019.

Anthesis of male flowers produced on diploid female 'Wife' plants began on 2 Jan. 2020. Hand-pollination of tetraploid 'Wife' plants with feminized (all female) diploid 'Wife' pollen occurred from 2 Jan. 2020 to 10 Jan. 2020. Tetraploid plants were used as the maternal parent, because the $2 n$ female gamete has been shown to be more efficient than $2 \mathrm{n}$ pollen for the formation of triploid pants (Wang et al., 2016). Feminized pollen was collected in $50-\mathrm{mL}$ conical tubes by gently agitating male flowers with a gloved finger to release pollen. Collected pollen was brushed on female tetraploid stigmas using a soft bristled paintbrush. Putative triploid seeds developed normally on tetraploid mothers for the first 2 weeks after pollination, at which time seed development appeared to arrest and seeds started to become soft. For this reason, on 24 Jan. 2020, embryo rescue was attempted for the remaining seeds that were firm. The majority of developing seeds failed, became soft, and were not useful. From tetraploid plants, 20 remaining seeds were harvested and surfacesterilized with $20 \%$ sodium hypochlorite solution, and the embryos were excised under sterile conditions. Fifteen embryos were excised successfully from the immature seeds and introduced into aseptic culture. Immature embryos were cultured in G7 magenta boxes containing $45 \mathrm{~mL}$ Murashige and Skoog medium supplemented with $3 \%$ sucrose, 2 $\mu \mathrm{M}$ meta-Topolin, and $0.8 \%$ agar at $\mathrm{pH} 5.7$. Seven embryos germinated (Fig. 1B) and were subcultured to the same medium on 21 Feb. 2020. At subculture, roots were removed from the embryos and hypocotyls were trimmed to $1 \mathrm{~cm}$ below the cotyledons to enhance expansion of the epicotyl. On 20 Mar. 2020, putative triploid shoots were rooted ex vitro in rockwool cubes. Four rooted plants were potted in 1-L containers using the same potting medium stated previously and acclimated to the greenhouse with set points as described and long days.

Flow cytometry. Flow cytometric analysis was used to determine ploidy level as was 
Table 1. Percent emergence, seedling height, and number of tetraploid and mixoploid plants produced per treatment from exposing pregerminated seeds of 'Abacas' $\times[($ 'Otto2' $\times$ 'BaOx') $\times($ 'BaOx' $\times$ 'Colorado Cherry')] to $0.02 \%$ or $0.05 \%$ colchicine for 6,12 , or $24 \mathrm{~h}$.

\begin{tabular}{|c|c|c|c|c|c|}
\hline Colchicine $(\%)$ & Duration (h) & Emergence $(\%)^{\mathrm{z}}$ & Seedling ht $(\mathrm{cm})$ & No. of tetraploid plants & No. of mixoploid plants \\
\hline 0 & 24 & $100 \mathrm{a}^{\mathrm{y}}$ & $4.9 \mathrm{a}$ & 0 & 0 \\
\hline 0.02 & 6 & $88 \mathrm{a}$ & $2.3 \mathrm{~b}$ & 0 & 0 \\
\hline 0.02 & 12 & $48 \mathrm{~b}$ & $1.1 \mathrm{c}$ & 3 & 2 \\
\hline 0.02 & 24 & $20 \mathrm{cb}$ & $0.2 \mathrm{dc}$ & 0 & 3 \\
\hline 0.05 & 6 & $36 \mathrm{cb}$ & $0.7 \mathrm{dc}$ & 1 & 3 \\
\hline 0.05 & 12 & $12 \mathrm{cb}$ & $0.3 \mathrm{dc}$ & 1 & 0 \\
\hline 0.05 & 24 & $8 \mathrm{c}$ & $0.1 \mathrm{~d}$ & 0 & 0 \\
\hline
\end{tabular}

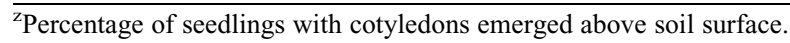

${ }^{\mathrm{y}}$ Mean separation within columns, indicated by different letters, using Tukey's honestly significant difference at $P \leq 0.05$ (n $=5$ ).

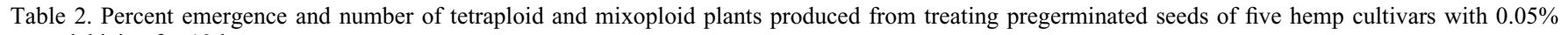
colchicine for $12 \mathrm{~h}$.

\begin{tabular}{|c|c|c|c|c|c|}
\hline Cultivar & $\mathrm{n}$ & Emergence $(\%)^{\mathrm{z}}$ & No. of tetraploid plants & No. of mixoploid plants & Tetraploid induction rate $(\%)^{\mathrm{y}}$ \\
\hline Abacus $\times$ Wife & 19 & 100 & 5 & 2 & 26 \\
\hline Cherry Wine & 20 & 90 & 7 & 2 & 35 \\
\hline Mountain Mango & 18 & 100 & 10 & 1 & 56 \\
\hline Wife & 9 & 78 & 3 & 4 & 33 \\
\hline Youngsim 10 & 22 & 91 & 14 & 2 & 64 \\
\hline
\end{tabular}

${ }^{\mathrm{z}}$ Number of seedlings with cotyledons emerged above soil surface.

${ }^{\mathrm{y}}$ Number of tetraploid plants divided by $\mathrm{n}$ and multiplied by $100 \%$.
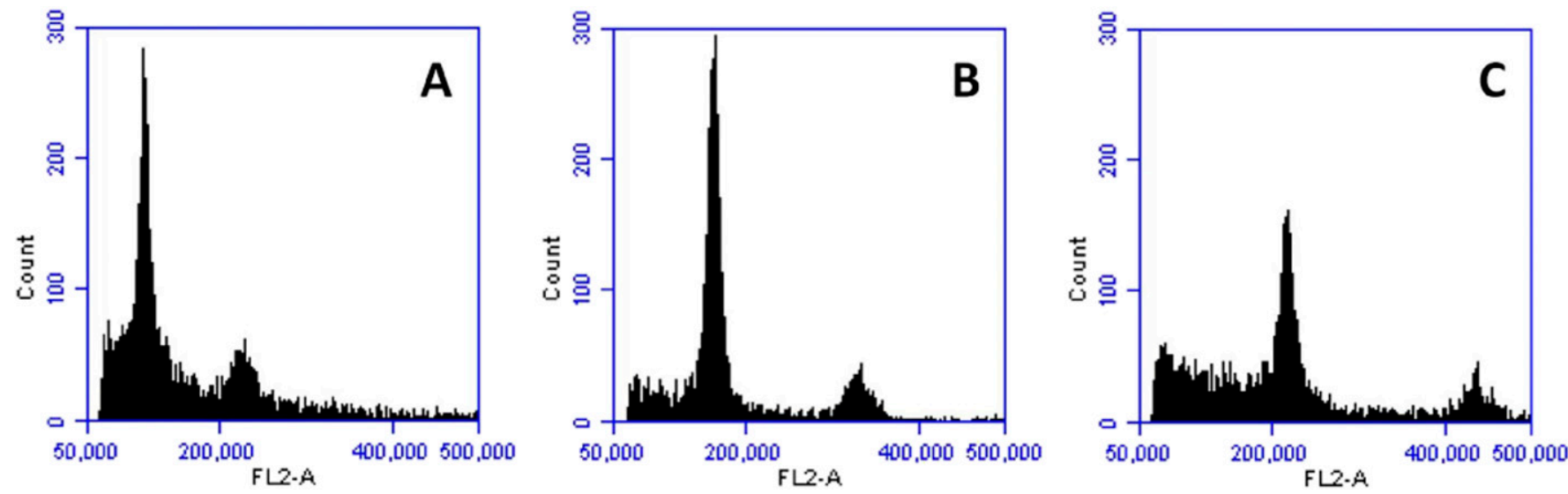

Fig. 2. Flow cytometric histograms representing hemp plants with (A) a diploid (2n) profile, $(\mathbf{B})$ a triploid (3n) profile, and (C) a tetraploid (4n) profile. FL2-A = relative fluorescence of total DNA.

Table 3. Stomata density, determined for an area of leaf measuring $0.04 \mathrm{~mm}^{2}$, and stomate length and width for diploid, triploid, and tetraploid plants of hemp cultivar Wife.

\begin{tabular}{lccc}
\hline Ploidy & Stomata density $\left(\mathrm{mm}^{2}\right)$ & Stomate length $(\mu \mathrm{m})$ & Stomate width $(\mu \mathrm{m})$ \\
\hline Diploid & $491.7 \mathrm{a}^{\mathrm{z}}$ & $17.0 \mathrm{c}$ & $13.3 \mathrm{c}$ \\
Triploid & $541.7 \mathrm{a}$ & $20.7 \mathrm{~b}$ & $16.9 \mathrm{~b}$ \\
Tetraploid & $300.0 \mathrm{~b}$ & $31.2 \mathrm{a}$ & $21.5 \mathrm{a}$ \\
\hline
\end{tabular}

${ }^{\mathrm{z}}$ Mean separation within columns, indicated by different letters, using Tukey's honestly significant difference at $P \leq 0.05(\mathrm{n}=3)$.

done for $C$. sativa by Bagheri and Mansouri (2015) and Parsons et al. (2019). For flow cytometric analysis, $50 \mathrm{mg}$ of young leaf tissue was harvested per plant. A modified version of the protocol noted in Arumuganathan and Earle (1991), and described in Lehrer et al. (2008) and Mahoney et al. (2019), was followed. Young leaves were chopped using a razor blade in nuclei suspending solution in a $55-\mathrm{mm}$ petri dish on ice. The suspending solution was filtered, centrifuged to form a pellet, and resuspended in nuclei staining solution containing propidium iodide. Relative fluorescence of total DNA (FL2-A) was measured using a flow cytometer (BD Accuri C6; BD Biosciences, San
Jose, CA). Data were displayed in histograms using BD Accuri C6 Software (1.0.264.21; BD Biosciences, San Jose, CA). To determine ploidy levels of putative tetraploids and triploids, their histogram peaks were compared with those derived from diploid hemp. Flow cytometric analysis was conducted five times over four clonal propagation cycles for three tetraploid 'Wife' genotypes to document ploidy stability.

Stomata characteristics. Stomata of diploid, triploid, and tetraploid genotypes of 'Wife' were evaluated. To visualize stomata, nail polish impressions of the abaxial surface of mature fan leaves were made for three leaves per genotype (Grant and Vatnick,
2004). Impressions were visualized using a compound microscope (Microphot-FXA; Nikon Instruments, Melville, NY) and microscopy camera (Infinity3; Teledyne Lumenera, Ottawa, $\mathrm{ON})$. Length and width for 10 stomata per leaf were measured at $10 \times$ magnification using ImageJ software (version $1.52 \mathrm{a} ; \mathrm{Na}$ tional Institutes of Health, Bethesda, MD). The number of stomata present in a $0.04-\mathrm{mm}^{2}$ area of leaf was counted. Stomata density was calculated by dividing the number of stomata by 0.04 .

Data were subjected to ANOVA (Proc GLM) using SAS (version 9.4; SAS Institute). Mean separation using Tukey's honestly significant difference test $(P \leq 0.05)$ 

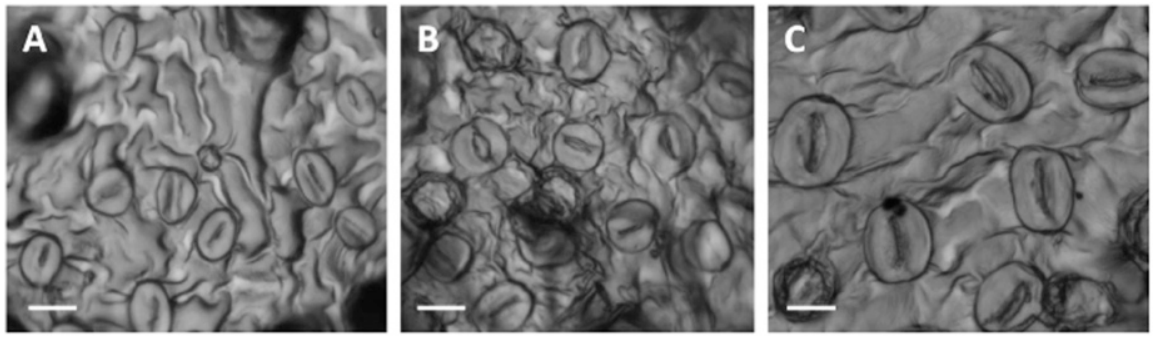

Fig. 3. Nail polish impressions showing stomata on the abaxial surface of (A) diploid (B) triploid and (C) tetraploid fan leaves. Scale bars $=20 \mu \mathrm{m}$.

was performed for stomata density and stomata length and width.

\section{Results and Discussion}

Colchicine-treated seedlings were significantly shorter than untreated control seedlings $10 \mathrm{~d}$ after sowing (Table 1). Seedlings treated with $0.02 \%$ colchicine for $24 \mathrm{~h}$ and $0.05 \%$ colchicine for all durations were less than $1 \mathrm{~cm}$ tall at $10 \mathrm{~d}$ after sowing and exhibited thickened cotyledons and hypocotyls (Fig. 1A, insert). Some of these seedlings failed to expand their epicotyl and perished. At $0.02 \%$ colchicine, percent emergence and seedling height decreased as duration of exposure to colchicine increased from 6 to 12 to $24 \mathrm{~h}$. In total, five tetraploids were produced from Expt. 1. Three of the five tetraploids were generated from exposure to $0.02 \%$ colchicine for $12 \mathrm{~h}$. This treatment also resulted in two mixoploids. The remaining two tetraploids were produced from exposure to $0.05 \%$ colchicine for 6 and $12 \mathrm{~h}$. At $0.05 \%$ colchicine, the 6 -h treatment produced three mixoploids, whereas the 12-h treatment produced no mixoploids.

For Expt. 2, our goal was to produce tetraploids of more desirable cultivars for which we had limited seed quantity. We decided to treat with $0.05 \%$ colchicine for $12 \mathrm{~h}$ to ensure production of only seedlings with short stature and thickened cotyledons and hypocotyl, and to minimize the number of mixoploids. Tetraploid induction ranged from $26 \%$ to $64 \%$, depending on the cultivar in Expt. 2 (Table 2). A total of 39 tetraploids were generated in Expt. 2, which is notably more than those generated in Expt. 1, which may be attributed to enhanced seed quality or genotype response to colchicine in Expt. 2 . More C. sativa tetraploids were produced using pregerminated seeds in Expt. 2 than were produced by Bagheri and Mansouri (2015) using 7-d-old seedlings and colchicine, and by Parsons et al. (2019) using nodal explants and oryzalin. We attempted tetraploid induction according to Bagheri and Mansouri (2015) using 0.2\% colchicine, but were unsuccessful at generating polyploids (data not shown). Our findings demonstrate that using pregerminated seeds and colchicine is an easy and effective method for producing tetraploids of hemp. This method was used successfully by Lehrer et al. (2008) to produce tetraploids of Japanese barberry.
Parsons et al. (2019) reported that the ploidy of induced tetraploids of $C$. sativa was stable through clonal propagation. We found for three induced tetraploid 'Wife' genotypes that ploidy was stable over four cycles of clonal propagation by stem cuttings.

Four triploid hemp genotypes were confirmed using flow cytometry and analysis of stomatal characteristics. Three genotypes had the parentage W1 $\times$ 'Wife' (Fig. 1C) and the fourth genotype had the parentage W2 $\times$ 'Wife'. FL2-A fluorescence of total DNA was 225,000 for the tetraploids, which is a $96 \%$ increase in DNA content over the diploids with FL2-A fluorescence of 115,000 (Fig. 2). Similarly, Bagheri and Mansouri (2015) and Parsons et al. (2019) found that the DNA content of tetraploid C. sativa was almost twice that of diploid C. sativa according to flow cytometric analysis. The FL2-A fluorescence of the triploid was 160,000, which is $40 \%$ more DNA than the diploid and $40 \%$ less DNA than the tetraploid. The intermediate FL2-A finding for triploid hemp was precisely what we expected for plants with 3 n chromosomes.

Stomate length and width for 'Wife' genotypes increased significantly as ploidy increased from diploid to triploid to tetraploid (Table 3, Fig. 3). Stomatal density was greater for diploid and triploid 'Wife' than for tetraploid 'Wife'. Parsons et al. (2019) found that tetraploid $C$. sativa had larger stomates and reduced stomatal density than diploid $C$. sativa. Similarly, for coffee, as ploidy level increased, stomate size increased and stomatal density decreased (Mishra, 1997). The larger cell sizes observed for tetraploid and triploid plants compared with diploids could be the result of increased copies of genes present for the polyploids (Sattler et al., 2016).

The method reported here of exposing pregerminated seed to a mitotic spindle inhibitor such as colchicine represents a relatively easy way to produce tetraploids of hemp. A possible drawback of this seedbased method is the genetic variability inherent in some seed. To our knowledge, this is the first report of triploid plants of hemp. Future research is needed to evaluate the sterility and growth performance of hemp triploids. Seedless triploids have been developed for hops, a close relative of $C$. sativa (Trojak-Goluch and Skomra, 2018). In addition to sterility, triploid hops have proved to be higher yielding and have increased alpha acids, which are important for aroma and flavor. It is possible that triploid hemp may offer some unique cannabinoid profiles or increased secondary metabolite content.

\section{Literature Cited}

Agriculture Marketing Service. 2019. Establishment of a domestic hemp production program. 13 May 2020. $<$ https://www.federalregister.gov/d/ 2019-23749>.

Alexander, L. 2017. Production of triploid Hydrangea macrophylla via unreduced gamete breeding. HortScience 52:221-224.

Arumuganathan, K. and E.D. Earle. 1991. Estimation of nuclear DNA content of plants by flow cytometry. Plant Mol. Biol. Rpt. 9:229-233.

Bagheri, M. and H. Mansouri. 2015. Effect of induced polyploidy on some biochemical parameters in Cannabis sativa L. Appl. Biochem. Biotechnol. 175:2366-2375.

Clarke, R.C. 1977. The botany and ecology of Cannabis. Pods Press, Ben Lomond, CA.

Grant, B.W. and I. Vatnick. 2004. Environmental correlates of leaf stomata density. Teach. Issues Exp. Ecol. 1:1-24.

Lehrer, J.M., M.H. Brand, and J.D. Lubell. 2008. Induction of tetraploidy in meristematically active seeds of Japanese barberry (Berberis thunbergii var. atropurpurea) through exposure to colchicine and oryzalin. Scientia Hort. 119:67-71.

Lubell, J.D. and M.H. Brand. 2018. Foliar sprays of silver thiosulfate produce male flowers on female hemp plants. HortTechnology 28:1-5.

Mahoney, J.D., T.M. Hau, B.A. Connolly, and M.H. Brand. 2019. Sexual and apomictic seed reproduction in Aronia species with different ploidy levels. HortScience 54:642646.

Mansouri, H. and M. Bagheri. 2017. Induction of polyploidy and its effect on Cannabis sativa L., p. 365-383. In: S. Chandra, H. Lata, and M. El Sohly (eds.). Cannabis sativa L.: Botany and biotechnology. Springer, Cham, Switzerland.

Meier, C. and V. Mediavilla. 1998. Factors influencing the yield and the quality of hemp (Cannabis sativa L.) essential oil. J. Intl. Hemp Assoc. 5:6-20.

Mishra, M.K. 1997. Stomatal characteristics at different ploidy levels in Coffea L. Ann. Bot. 80:689-692.

Moliterni, V.M.C., L. Cattivelli, P. Ranalli, and G. Mandolino. 2004. The sexual differentiation of Cannabis sativa L.: A morphological and molecular study. Euphytica 140:95-106.

Neiden, C. 2020. Step up your growing game: 21 Tips from researchers and farmers. Hemp Grower. 29 May 2020. <https://www.hempgrower.com/ article/21-hemp-growing-tips-researchers-farmerspart-1/>.

Parsons, J.L., S.L. Martin, T. James, G. Golenia, E.A. Boudko, and S.R. Hepworth. 2019. Polyploidization for the genetic improvement of Cannabis sativa. Frontiers Plant Sci. 10:476.

Perkowski, M. 2019. Hemp boom spurs crosspollination disputes. Capital Press. 29 May 2020. $<$ https://www.capitalpress.com/state/ oregon/hemp-boom-spurs-cross-pollinationdisputes/article_efd1e99c-c903-11e9-8bdd73e58f5946b5.html>.

Sattler, M.C., C.R. Carvalho, and W.R. Clarindo. 2016. The polyploidy and its key role in plant breeding. Planta 243:281-296. 
Sharma, V., D.K. Srivastava, R.C. Gupta, and B. Singh. 2015. Abnormal meiosis in tetraploid (4x) Cannabis sativa (L.) from Lahaul-Spiti (cold desert higher altitude Himalayas): A neglected but important herb. J. Biol. Chem. Chron. 2:38-42.

Small, E. 2015. Evolution and classification of Cannabis sativa (marijuana, hemp) in relation to human utilization. Bot. Rev. 81:189-294.
Small, E. and A. Cronquist. 1976. A practical and natural taxonomy for Cannabis. Taxon 25:405435.

Trojak-Goluch, A. and U. Skomra. 2018. Breeding of triploid common hop cultivars (Humulus lupulus L.). Polish J. Agron. 34:3-10.

Wang, X., Z.M. Cheng, S. Zhi, and F. Xu. 2016. Breeding triploid plants: A review. Czech J. Genet. Plant Breed. 52:41-54.
Warmke, H.E. and H. Davidson. 1944. Polyploidy investigations. Year B Carnegie Inst. Wash. 43:135-139.

Xu, C.G., T.X. Tang, R. Chen, C.H. Liang, X.Y. Liu, C.L. Wu, Y.S. Yang, D.P. Yang, and H. Wu. 2014. A comparative study of bioactive secondary metabolite production in diploid and tetraploid Echinacea purpurea (L.) Moench. Plant Cell Tissue Organ Cult. 116:323-332. 